\title{
In-pile Test Results of U-Silicide or U-Nitride Coated U-7Mo Particle Dispersion Fuel in Al
}

\author{
Yeon Soo Kim, J.M. Park, K.H. Lee, B.O. Yoo, H.J. Ryu, B. Ye
}

\begin{abstract}
U-silicide or U-nitride coated U-Mo particle dispersion fuel in $\mathrm{Al}$ (U-Mo/Al) was in-pile tested to examine the effectiveness of the coating as a diffusion barrier between the U7Mo fuel kernels and $\mathrm{Al}$ matrix. This paper reports the PIE data and analyses focusing on the effectiveness of the coating in terms of interaction layer (IL) growth and general fuel performance. The U-silicide coating showed considerable success, but it also provided evidence for additional improvement for coating process. The U-nitride coated specimen showed largely inefficient results in reducing IL growth. From the test, important observations were also made that can be utilized to improve $\mathrm{U}-\mathrm{Mo} / \mathrm{Al}$ fuel performance. The heating process for coating turned out to be beneficial to suppress fuel swelling. The use of larger fuel particles confirmed favorable effects on fuel performance.
\end{abstract}

Keywords: U-Mo/Al, dispersion fuel, coated U-Mo, U-silicide coating, U-nitride coating, in-pile test, PIE, research/test reactor fuel, LEU

(C) 2014. This manuscript version is made available under the Elsevier user license http://www.elsevier.com/open-access/userlicense/1.0/ 


\section{Introduction}

For the LEU conversion of HEU-using research and test reactors, uranium density in the fuel meat has to be increased to compensate the reduced U-235 enrichment. This calls for the use of a high density fuel and a raise in fuel volume in the meat. In the development of high-density UMo particle fuel dispersed in Al matrix, designated U-Mo/Al hereafter, interaction layer (IL) growth between the U-Mo particles and Al considerably degrades fuel performance due to heightened fuel volume fraction in the fuel meat. To suppress IL growth, a small amount of Si addition to Al matrix was proposed at ANL [1][2]. This remedy has proved effective in many out-of-pile, in-pile and ion beam irradiation tests [3]-[34]. It was also found that the suppression in IL growth increased with Si content [35]. This method is convenient to apply in that it requires neither considerable extra-cost nor technological improvement in the current hot-rolling fabrication method. Despite being beneficial in general, the effectiveness of Si addition in Al matrix weakens when the Si distribution in the matrix is inhomogeneous and/or the fuel particle distribution is inhomogeneous. To boost the effectiveness of Si addition to achieve high-power and high-burnup, increasing Si contents in Al matrix appeared logical. However, this increases the matrix toughness [36], which makes plate fabrication more difficult and fuel particle distribution more inhomogeneous. The maximum Si content compatible with reasonable fuel homogeneity appeared to be about $6 \%$ for the current hot-rolling technology [36], which is insufficient for conditions required for high performance reactors.

To overcome these disadvantages, providing a direct diffusion barrier on U-Mo particles before plate fabrication has been proposed [37]-[39]. KAERI's method is to coat the fuel particles with 
a reaction layer of $U$-silicide formed in a high-temperature heating process. In addition, KAERI also invented a U-nitride coating method. One of the objectives of KAERI's KOMO-5 test was to determine the effectiveness of the coating methods. This paper reports the PIE data of the test and analyses focusing on the effectiveness of the coating layers with regard to IL growth and general fuel performance. Although the KOMO-5 tested specifically U-7Mo as the fuel kernel, the PIE data and analyses reported in this paper are deemed applicable to other Mo contents in the range $7-10 \mathrm{wt} . \%$.

\section{Experimental}

\subsection{Test specimen fabrication}

The U-silicide coating method is illustrated in Fig. 1 [39],[40]. U-7Mo alloy particles, U alloyed with 7 wt.\% Mo, manufactured using KAERI's atomization method [41] were mixed with Si powder having $99 \%$ in purity and size of -325 mesh $(=44 \mu \mathrm{m})$. The $\mathrm{U}-235$ enrichment was 19.75\%. Although the nominal Mo composition was set 7 wt.\%, the chemical analysis of atomized particles showed that the actual Mo content was 6.2 wt.\% (see Table 1). The mixture was then heated in a vacuum of $1 \mathrm{~Pa}$ at $1000{ }^{\circ} \mathrm{C}$ for one hour [40]. As a result of the heating, a Usilicide coating layer was formed on the U-7Mo particles with a thickness of $\sim 5 \mu \mathrm{m}$. The coating layer in U-Mo/Al was examined using scanning electron microscopy (SEM) (Fig. 2). It appears that two sub-layers were formed, the outer one thicker than the inner. The X-ray diffraction study showed that the outer layer was close to $\mathrm{U}_{3} \mathrm{Si}_{5}$ and the inner layer $\mathrm{U}_{4} \mathrm{Mo}\left(\mathrm{Mo}_{\mathrm{x}} \mathrm{Si}_{1-\mathrm{x}}\right) \mathrm{Si}_{2}$ [42], so the $\mathrm{Si} / \mathrm{U}$ ratio of the outer layer was approximately 1.6, while that of the inner layer was 
approximately 0.6. The amount of $\mathrm{Si}$ in the coating layer was calculated to be about $4 \mathrm{wt} \%$ of $\mathrm{Si}$ addition in the matrix based on $5 \mathrm{gU} / \mathrm{cm}^{3}$ loading. The external surface of the coating layer was smooth compared to the inner surface on U-7Mo.

Typical U-Mo particles produced by the KAERI atomization method built a $\mathrm{U}(\mathrm{Mo}) \mathrm{O}_{2}$ type oxide with $\sim 1.5 \mu \mathrm{m}$ thickness on its surface. After the coating process, a substantial oxygen level was found in the coating layer originally from this oxide layer as well as oxygen impurity during the coating [39].

KAERI also developed a U-nitride coating technology, in which the atomized U-7Mo particles were heated at $1000{ }^{\circ} \mathrm{C}$ for one hour in a controlled nitrogen and argon gas mixture, illustrated in Fig. 3. During the heating, the cylindrical $\mathrm{ZrO}_{2}$ crucible was horizontally placed in the heating unit and rotated about the axial centerline to promote uniform coating. Characterization of the ascoated U-7Mo particles indicated that a coating layer of U-nitride with a thickness of $\sim 5 \mu \mathrm{m}$ was formed. Energy dispersive spectroscopy (EDS) was also performed to measure the elemental concentrations of the coating layer, as marked A in Fig. 4. A substantial nitrogen concentration was measured in the coating layer, higher than that for UN. A former X-ray diffraction study of the U-nitride coated U-Mo/Al dispersion fuel reported that the U-nitride coating layer was UN [42], suggesting the EDS result for the nitrogen concentration was exaggerated. The considerable oxygen content in the coating layer was attributed to the oxide layer formed on the fuel particle before coating and oxygen impurity during coating [43]. Another finding from the EDS result was that the Mo concentration in the coating layer was much lower than the value of the inner regions in the fuel particle. This is probably due to the lower affinity of Mo than uranium for 
nitrogen. The Mo concentration in the fuel particle measured after atomization was $\sim 16$ at $\%$ or 7 wt.\%, as given in Table 1.

The size of coated U-Mo particles was controlled between $140-210 \mu \mathrm{m}$. Particle agglomeration by sintering during the coating process was inconsiderable.

The test rod specimens were 200-mm long, composing only a part of the 700-mm long full size test rods. The rest was dummy Al. They contained cylindrical fuel meat of the coated U-7Mo particles dispersed in $\mathrm{Al}$ matrix. The fuel meat was $6.4 \mathrm{~mm}$ in diameter and was directly bonded to Al-1060 cladding of $0.76 \mathrm{~mm}$ in thickness. The cladding had 8 fins with height of $\sim 1 \mathrm{~mm}$ to improve heat transfer, the same as the HANARO driver fuel rods. The U-density in the meat was $5 \mathrm{gU} / \mathrm{cm}^{3}$-meat. The fuel particle size ranging $140-210 \mu \mathrm{m}$ is significantly enlarged from the typical size of $\sim 70 \mu \mathrm{m}$ adopted in the US RERTR and European tests. The U-silicide coated fuel rod (557-SI1) and U-nitride coated fuel rod (676-NI1) were loaded in the fuel rod test bundle as illustrated in Fig. 5.

2.2 Irradiation test and post irradiation examination (PIE)

The test rod bundle was irradiated in the HANARO reactor in KAERI for 228 EFPD. The calculated peak temperature and power histories of 557-SI1 and 676-NI1 at their PIE locations are shown in Fig. 6. Table 1 also includes irradiation conditions for the specimens studied in the present study. 
After completion of the irradiation and cooling in the reactor pool, the test bundle was transported to the IMEF hot cell in KAERI for non-destructive and destructive examinations. The rod specimen 557-SI1 was cut at $191 \mathrm{~mm}$ measured from the upper end plug while 676-NI1 was cut at $178 \mathrm{~mm}$. A PIE sample was made out of one of the cut surfaces. Because the test rod specimens were loaded in the upper region of the full size rods and the reactor axial power shape was a chopped-cosine shape, the lower part of the specimens achieved higher power and burnup. Consequently, the temperature was also higher at a lower part of the specimens. Although 676NI1 was closer than 557-SI1 to the reactor core center (Fig. 5), the PIE sample of 676-NI1 had lower power, burnup and temperature than those of 557-SI1 because the former was cut at a higher location than the latter. The PIE sample of 557-SI1 attained burnup of $68 \%$ LEU equivalent burnup (or 13.4\% fission per initial heavy metal atom (FIHMA)) and that of 676-NI1 $62 \%$ LEU equivalent burnup (or $12.2 \%$ FIHMA).

The PIE samples were polished and prepared for optical microscopy (OM) and SEM. EDS was also used to measure elemental composition in the ILs, coatings and U-Mo surfaces.

\section{Results}

The effectiveness of the U-silicide coating was evaluated by measuring the IL thickness and meat swelling using OM. The OM images with higher magnification were assembled to display the entire cross sections. The image presented in Fig. 7(a) provides a partial radial cross section of 557-SI1. 
It appears that three kinds of ILs were formed in 557-SI1: an IL with apparently minimal thickness, a less thick but irregular IL, and a thick and uniform IL. This observation suggests that the quality of the coating layer was variable. When the coating was perfect, it virtually suppressed IL growth completely. When it was imperfect, it yielded some IL growth. When it was removed or no coating was formed during the coating procedure, IL growth was not suppressed.

The IL growth behavior in 676-NI1 was also examined using OM images. The image presented in Fig. 7(b) is an assembly of many higher magnification OM images. The ILs are more uniform than in 557-SI1, implying that the coating layer was more uniform. In the U-nitride coating process, the coating agent was a gas phase, so more even reactions might occur on U-Mo particle surface than in the U-silicide coating process.

The average IL thickness in 557-SI1 was $\sim 22 \mu \mathrm{m}$ while that in $676-\mathrm{NI} 1$ was $\sim 27 \mu \mathrm{m}$. The IL volume fractions for $557-$ SI1 and $676-$ NI1 were $26 \%$ and $29 \%$, respectively. This result suggested that the U-silicide coating was slightly superior to the U-nitride coating in terms of IL growth.

In the test cylindrical rod, the meat dimensional change in axial direction is negligible due to higher constraint. Fuel meat swelling takes place to expand the radial cross sectional area. We measured the meat diameter change before and after the irradiation and calculated the meat swelling by the following equation:

$\left(\frac{\Delta \mathrm{V}}{\mathrm{V}_{0}}\right)_{\mathrm{m}}=\frac{\mathrm{D}_{\mathrm{m}}^{2}-\mathrm{D}_{\mathrm{m}, 0}^{2}}{\mathrm{D}_{\mathrm{m}, 0}^{2}}$

where the subscript $\mathrm{m}$ denotes the meat, $\mathrm{D}$ is the meat diameter, and the subscript 0 stands for asfabrication. The measured meat swelling according to Eq.(1) was $10 \%$ for $557-$ SI1 and $9 \%$ for 
676-NI1. Considering the higher burnup for 557-SI1, the only slightly greater meat swelling for 557-SI1 is attributed to the lower IL growth in this specimen.

EDS measurements in the ILs were made. Two kinds of ILs were analyzed for 557-SI1: one with thin IL (A and a in Fig. 8), and the other with thick IL (B and b in Fig. 8). It was noticeable that the thin IL was formed on the U-silicide coating while the thick IL was formed on the U-7Mo surface. Compared with the as-coated elemental composition, however, $\mathrm{Si}$ in the coating layer appeared to be diluted considerably during the irradiation.

For 676-NI1, the nitrogen concentration was negligible in and around the IL (C and c in Fig. 8). Through OM and SEM, no U-nitride coating layer was observed, implying that the U-nitride coating layer had dissolved and disappeared during irradiation. The thick and uniform IL formation is analogous to that of U-7Mo dispersion fuel in pure Al. Consequently, we deduce that the U-nitride coating layer on the U-7Mo surface was inefficient as a diffusion barrier against Al.

Higher magnification images in Fig. 9 clearly contrast the difference in the ILs between 557-SI1 and 676-NI1. Irregular ILs are prominent in 557-SI1 whereas more uniform ILs are seen in 676NI1. Both specimens in Fig. 9 had large grains in the U-Mo particles such as $~ 25 \mu \mathrm{m}$ for $557-$ SI1 and $\sim 50 \mu \mathrm{m}$ for $676-\mathrm{NI} 1$. The grain boundaries are visible in lighter lines in the U-Mo particles marked by 1 and 2 in Fig. 9. Considering the typical grain size of $\sim 10 \mu \mathrm{m}$ observed for uncoated fuel particles [44], we suppose that the grains had grown considerably during the coating process at $1000{ }^{\circ} \mathrm{C}$ for one hour. The smaller grain size for the U-silicide coated particle than the U-nitride 
coated particle may be due to the higher grain refinement, which will be discussed in the following section, caused by higher burnup and by lower Mo content in the fuel particle. A U-Mo fuel with lower Mo content is known to show a higher rate of grain refinement [45].

Fig. 10 compares SEM images of post-irradiation 557-SI1 and 676-NI1. In the U-nitride coated U-7Mo fuel, fission gas bubbles (FGB) are absent in the fuel periphery regions in contrast to the U-silicide coated U-7Mo fuel in Fig. 10(a), which revealed considerable population of FGB. The small difference in burnup between the two specimens cannot explain the cause for this difference.

\section{Discussion}

\subsection{Effectiveness of U-silicide coating and U-nitride coating}

The U-silicide coating on U-7Mo particles proved effective as a diffusion barrier to lessen $\mathrm{Al}$ diffusion in the IL between U-7Mo and Al. This is consistent with the previous observation from the test of the Si addition to Al matrix [3]. Since the U-silicide coating is more effective to provide $\mathrm{Si}$ on the U-7Mo surface, the IL-reducing effect would be stronger than $\mathrm{Si}$ addition to $\mathrm{Al}$ matrix.

The irregular ILs hint that the U-silicide coating layers were non-uniform and might be different in quality. Since the coating method practically transforms the fuel particle periphery to a Usilicide fuel, the removal of the coating during test rod fabrication would probably be difficult. 
Hence, it is reasonable to assume that most of the low-quality and no-coat regions occurred during the coating process. Therefore, applying a uniform coating layer seems to be the key to improving the effectiveness of the U-silicide coating and upgrading fuel performance. The use of a continuously tumbling bed during coating is a possible candidate.

In Fig. 8(A) and (a) and Fig. 10(a), it is observable that the IL was formed on the U-silicide coating. This result indicates that $\mathrm{Al}$ has reacted with $\mathrm{U}$ in the $\mathrm{U}$-silicide coating layer, in the same manner as in $\mathrm{U}_{3} \mathrm{Si}_{2} / \mathrm{Al}$ dispersion fuel [46]. As was mentioned earlier, the IL growth mechanism between the $\mathrm{U}$-silicide coating layer and $\mathrm{Al}$ is probably similar to that of $\mathrm{U}_{3} \mathrm{Si}$ or $\mathrm{U}_{3} \mathrm{Si}_{2}$ dispersion fuel in $\mathrm{Al}$. The IL thickness measured at $\mathrm{A}$ in Fig. 9 (a) is $\sim 30 \mu \mathrm{m}$, at B is $\sim 5 \mu \mathrm{m}$ and at $\mathrm{C} \sim 0 \mu \mathrm{m}$. This heterogeneous IL growth has not been observed in the previous tests of non-coating U-Mo dispersion fuel in pure Al. We predicted IL thickness using available empirical models, with inputs of life-averaged fission rates and temperatures, that are applicable to non-coated U-Mo/Al [35] and U-silicide dispersion fuel in pure $\mathrm{Al}$ [46]. The calculated IL thickness at EOL for non-coating U-Mo/Al dispersion fuel was $33 \mu \mathrm{m}$, which is close to the measured value at A in Fig. 9(a). This result suggested that the U-silicide coating was absent at A in Fig. 9(a). The IL thickness calculated using the correlation for $\mathrm{U}_{3} \mathrm{Si}_{2} / \mathrm{Al}$ [46] was $4 \mu \mathrm{m}$, which is close to the measured value at $\mathrm{B}$. Therefore, the effectiveness of the coating at $\mathrm{B}$ is analogous to that of $\mathrm{U}_{3} \mathrm{Si}_{2}$ dispersion in $\mathrm{Al}$. The negligible IL growth at $\mathrm{C}$ is remarkable. The possible reason is that the $\mathrm{Si}$ content in the coating layer at this surface was high enough to suppress interdiffusion of $\mathrm{Al}$ through the coating layer. The IL growth rate tends to be inversely dependent on the $\mathrm{Si} / \mathrm{U}$ ratio [46]. 
The effectiveness of the U-nitride coating layer as a diffusion barrier during irradiation appeared to be small. Using the same method as the U-Silicide coating case, we predicted the IL thickness to be $29 \mu \mathrm{m}$, which is slightly larger than the measured $27 \mu \mathrm{m}$ (Fig. 9(b)). This small difference confirmed that the U-nitride coating layer was not effective as a diffusion barrier.

EDS measurement of nitrogen in the IL was negligible and failed to find nitrogen accumulation in the U-7Mo surface regions where the U-nitride coating was found in the as-fabrication sample shown in Fig. 4, implying that the U-nitride coating had vanished. In an out-of-pile heating test, however, the U-nitride coating was intact as an effective diffusion barrier against Al diffusion. During the in-pile test, however, nitrogen might have migrated and diluted into Al matrix and possibly into the U-7Mo fuel. One possible mechanism would be fission product induced resolution of the U-nitride coating layer and fission-enhanced diffusion of nitrogen in the U-7Mo fuel and $\mathrm{Al}$ matrix. When the U-nitride coating layer is dissolved, $\mathrm{U}$ atoms can react with $\mathrm{Al}$, liberating nitrogen atoms by the following reaction:

$\mathrm{UN}+4 \mathrm{Al} \rightarrow \mathrm{UAl}_{4}+\mathrm{N}$

The liberated nitrogen atoms can then diffuse into $\mathrm{Al}$ matrix and U-7Mo. By this process, nitrogen can be diluted below the EDS-measurable limit.

From the KOMO-5 result, the U-nitride coating layer is concluded to be ineffective as a diffusion barrier, contrasting to the positive results for $\mathrm{ZrN}$ coating reported in [37],[38]. Hence, this method is judged not to be pursued further. However, the U-nitride coating specimen showed a 
worth noting benefit regarding fission gas bubble swelling. A comparison between the images for the U-silicide coating and for the U-nitride coating given in Fig. 10 provides a noticeable difference in fission gas bubble behavior. The U-nitride coating specimen appears to be better with respect to fission gas bubble swelling. As mentioned earlier, this may be due to the slightly higher burnup and the lower Mo content in the fuel particles of the U-silicide coating specimen. The U-silicide coated U-7Mo has a wider band of FGB along the grain boundaries than the Unitride coated U-7Mo. FGB are found at the U-7Mo surface in the U-silicide coated U-7Mo whereas no FGB are visible in this region of the U-nitride coated U-7Mo.

FGB are known to form first on the pre-existing grain boundaries. As recrystallization (or grain refinement) progresses, additional FGB form on the newly formed grain boundaries [45]. In this regard, it appears that the U-silicide coated U-7Mo fuel underwent more recrystallization than the U-nitride coated U-7Mo fuel. A possible reason for this higher recrystallization is related to high bubble growth in the U-rich U-silicide fuel in the peripheral regions of the U-7Mo particle. FGB produce higher stress that yields more defects such as dislocation loops, which provide the driving force for recrystallization [45].

In the region with high fission gas bubble growth, recrystallization enhances and increasingly recrystallized fuel also feeds back into more fission gas bubble formation. Only a small bit of recrystallization along the grain boundaries and subsequent fission gas bubble formation occurred in the U-nitride coated U-7Mo fuel. This observation can be explained by the stable fission gas bubble swelling characteristic of U-nitride fuel [47]. 
Because the U-silicide coating layer is in fact a fuel, the coated fuel particle is a 'duplex' fuel composed of a U-silicide fuel at the periphery and U-7Mo fuel in the interior. Hence, a true sideby-side comparison between U-silicide fuel and U-7Mo fuel might be possible. It is noticeable in Fig. 10(a) that larger bubbles than the typical inter-granular FGB in U-7Mo fuel were formed in the region between the U-silicide coating and U-7Mo fuel. In this region, the $\mathrm{Si} / \mathrm{U}$ ratio was probably low before irradiation as seen in Fig. 2. Hence, these bubbles were formed in the Usilicide with a lower $\mathrm{Si} / \mathrm{U}$ ratio than that of $\mathrm{U}_{3} \mathrm{Si}$. A similar observation was made also in U-Mo dispersion fuel in Si-added Al matrix [48],[49]. No visible FGB were found in the U-silicide coating layer, implying that in the coating layer with a high $\mathrm{Si} / \mathrm{U}$ ratio fission gas bubble growth was slow.

In the U-nitride coated U-Mo fuel, the thicker IL intruded on the grain boundary region. This may be due to a lower in Mo content in the grain boundaries than the grain interior. IL growth is higher there as discussed in Ref.[35]. In addition, in the fission gas bubble band (marked in Fig. 10(b)) the diffusion becomes faster due to the reduced diffusion area by the FGB.

\subsection{Heating effect during coating}

The heating process during coating appeared to improve the performance of U-7Mo fuel particles by growing grains and perhaps by annealing as-fabricated defects. The exceptionally large grains formed in the coated particles were attributed to the heat treatment during coating. The large fuel particles from the atomization method [41] tend to have larger grains due to slower cooling. The average grain size was $\sim 10 \mu \mathrm{m}$ for the fuel particles having size of $175 \mu \mathrm{m}$ 
while it was $\sim 4 \mu \mathrm{m}$ for the fuel particles having the size of $70 \mu \mathrm{m}$ [44]. Hence, the large grains with an average size of $\sim 50 \mu \mathrm{m}$ is attributed to grain growth during coating. The large grains reduce the recrystallization rate since recrystallization occurs at the pre-existing grain boundaries. In addition, the heating perhaps also annealed the defects formed during particle fabrication to some extent. Fewer defects in the fuel particles tend to increase the incubation time for recrystallization [45]. The slow and delayed recrystallization in the fuel particles is beneficial for lowering fuel swelling.

The heating was performed for both U-silicide coating and U-nitride coating at $1000{ }^{\circ} \mathrm{C}$ in the $\gamma$ phase. Deleterious $\alpha$-phase transformation did not occur; grain growth and defect annealing occurred. The effect of the $\gamma$-phase annealing was also tested in US (RERTR-3 test) and the advantageous results were observed [50]. The present results confirmed the favorable RERTR-3 test results.

\subsection{Use of large fuel particles}

The U-7Mo particle size was in the range $140-210 \mu \mathrm{m}$, which is much larger than the typical size used in the US RERTR tests and European tests $(\sim 70 \mu \mathrm{m})$. The use of large fuel particles was possible in the present test since the test rods were fabricated by using the co-extrusion method other than a rolling method for plates. In general, the homogeneity of fuel particle distribution in a rolled plate decreases when the particle size increases, making the use of large fuel particles unfavorable. Nevertheless, the following advantages achievable by the use of large particles may be worthwhile for higher-power and high-burnup conditions. 
The use of large fuel particles in a dispersion fuel form lowers IL growth by improving meat thermal conductivity, and, hence, by reducing the fuel temperature at the same power. Even at the same IL growth, the use of larger particles reduces the IL volume fraction in the meat by decreasing the specific surface area. Lower IL volume fraction in the meat means lower meat swelling. In addition, fission product recoil release is also reduced because it is also proportional to the specific surface area of fuel particles [3],[51].

DART [52] was used to estimate meat swelling for three fuel particle sizes. In the DART modeling, fuel meat swelling is the sum of fission product swelling in fuel particles and volume expansion in ILs, subtracted by volume consumptions in fuel particles and Al matrix by IL growth. Using the same irradiation condition for 557-SI1, i.e., power history, $68 \%$ burnup and 228 EFPD, the temperature was adjusted to yield the IL thickness $\sim 22 \mu \mathrm{m}$, which is the measured value. This step was necessary because there is no IL growth model available for a coated fuel dispersion in Al. The results are summarized in Table 2. While the average fuel particle size of $175 \mu \mathrm{m}$, which is the actual size used in the present test, gives fuel meat swelling of $9 \%$, the smaller fuel particle sizes gave larger values. The case for the fuel-particle size of 70 $\mu \mathrm{m}$ corresponds to the typical size used for RERTR tests and European tests. The fuel meat swelling was higher by $5 \%$ than that for 557-SI1. Furthermore, the Al matrix was completely consumed before the end of life, which was also observed for a previous test at KAERI with the similar fuel-particle size [53]. This calculation and the present test result reconfirm the previously reported results [48],[53] that fuel meat swelling can be reduced by using large fuel particles. Although this result was obtained for the rod type test, the same benefit would be 
expected for plate type fuels. Hence, it is recommended to increase fuel-particle size up to a level that does not significantly decrease the homogeneity of fuel-particle distribution in the fuel meat.

\section{Conclusions}

From the KOMO-5 irradiation test of the U-silicide coated U-7Mo dispersion fuel in $\mathrm{Al}$ and $\mathrm{U}$ nitride coated U-7Mo dispersion fuel in Al, the following conclusions can be drawn.

The post-irradiation examinations found that the U-silicide coating on U-7Mo particles improved fuel performance. IL growth between U-7Mo and $\mathrm{Al}$ was clearly reduced when the coating remained intact. However, the present results also revealed areas of improvement for coating process. The key improvement area is to provide uniform coating on the fuel particles and improve the coating layer quality.

The U-nitride coating method failed to present considerable advantages to provide a diffusion barrier between U-7Mo and Al to warrant further development. Reduction in IL growth was smaller than the U-silicide coating. After irradiation, the U-nitride coating could not be found. We suspect that the U-nitride coating was dissolved by fission fragments during irradiation, and the freed nitrogen atoms diffused in U-7Mo and Al. Therefore, unless other remedy is available, further pursuing of this method appears to be unworthy.

The heating during coating at $1000{ }^{\circ} \mathrm{C}$ for one hour provided an advantageous side effect. The grains in the U-7Mo particles grew and defects that were introduced during particle fabrication 
seemed to be annealed, both of which are known to delay recrystallization in fuel particles.

Hence, reduction in formation and growth of fission gas bubble may be expected. From this observation, an intentional heating of the U-Mo alloy particles at $\gamma$-phase temperatures before plate manufacturing is recommended.

The use of large fuel particles provided convincing results that reduced IL growth and meat swelling. A DART calculation supported that the use of large fuel particles, even with the same IL growth, was advantageous to reduction of meat swelling. Therefore, increasing fuel particle size warrants further development to realize the use of U-Mo/Al dispersion fuel for high-power and high-burnup conditions.

\section{ACKNOWLEDGMENT}

This study was supported by the National Research Foundation of Korea(NRF) grant funded by the Ministry of Science, ICT and Future Planning(MSIP) of Republic of Korea (NRF2013M2A8A1041241) and the ANL contribution was supported by the UChicago Argonne, LCC as Operator of Argonne National Laboratory under Contract No.DE-AC-02-06CH11357 between UChicago Argonne, LLC and the US Department of Energy.

\section{REFERENCES}

[1] G.L. Hofman, M.R. Finlay, Yeon Soo Kim, Proc. Internat. Mtg. on Reduced Enrichment for Research and Test Reactors (RERTR), Vienna, Austria, Nov. 7-12, 2004. $\langle$ http://www.rertr.anl.gov>

[2] Yeon Soo Kim, G.L. Hofman, H.J. Ryu, J. Rest, Proc. Internat. Mtg. on Reduced Enrichment for Research and Test Reactors (RERTR), Boston, USA, Nov. 6-10, 2005. $<$ http://www.rertr.anl.gov>

[3] Yeon Soo Kim, G.L. Hofman, A.B. Robinson, D.M. Wachs, Nucl. Technol., 184 (2013) 42.

[4] J.M. Park, H. Ryu, G. Lee, H. Kim, Y. Lee, C. Kim, Yeon Soo Kim, G.L. Hofman, Proc. Internat. Mtg. on Reduced Enrichment for Research and Test Reactors (RERTR), Boston, USA, Nov. 6-10, 2005. 〈http://www.rertr.anl.gov> 
[5] M. Mirandou, S. Arico, L. Gribaudo, and S. Balart, Proc. Internat. Mtg. on Reduced Enrichment for Research and Test Reactors (RERTR), Boston, USA, Nov. 6-10, 2005. $<$ http://www.rertr.anl.gov>

[6] M. Cornen, M. Rodier, X. Iltis, S. Dubois, P. Lemoine, Trans. Internat. Topical Meeting Research Reactor Fuel Management (RRFM), Hamburg, Germany, Mar. 2-5, 2008. 〈http://www.euronuclear.org/meetings/rrfm2008/index.htm>

[7] J.M. Park, H.J. Ryu, S.J. Oh, D.B. Lee, C.K. Kim, Yeon Soo Kim, G. L. Hofman, J. Nucl. Mater., 374 (2008) 422.

[8] M. Mirandou, S. Arico, M. Rosenbusch, M. Ortiz, S. Balart, L. Gribaudo, J. Nucl. Mater., 384 (2009) 268.

[9] M. Mirandou, S. Arico, S. Balart, L. Gribaudo, Mat. Charact. 60 (2009) 888.

[10] E. Perez, B. Yao, Y.H. Sohn, D.D. Keiser, Jr. Proc. Internat. Mtg. on Reduced Enrichment for Research and Test Reactors (RERTR), November 1-5, 2009, Beijing, China. $<$ http://www.rertr.anl.gov>

[11] J.H. Yang, H.J. Ryu, J.M. Park, Proc. Internat. Meeting Reduced Enrichment for research Test Reactors (RERTR), Beijing, China, Nov. 1-6, 2009. 〈http://www.rertr.anl.gov〉

[12] J.H. Allenou, H. Palancher, X. Iltis, M. Cornen, O. Tougait, R. Tucoulou, E. Welcomme, $\mathrm{Ph}$. Martin, C. Valot, F. Charollais, M. C. Anselmet, P. Lemoine, J. Nucl. Mater., 399 (2010) 189.

[13] D.D. Keiser, J. Jue, B. Yao, E. Perez, Y. Sohn, C.R. Clark, J. Nucl. Mater., 412 (2011) 90.

[14] G.L. Hofman, Yeon Soo Kim, J. Rest, M.R. Finlay, Trans. Internat. Topical Meeting Research Reactor Fuel Management (RRFM), Sofia, Bulgaria, April 30-May 3, 2006. <http://www.euronuclear.org/meetings/rrfm2006/index.htm>

[15] G.L. Hofman, Yeon Soo Kim, H.J. Ryu, D. Wachs, M.R. Finlay, Proc. Internat. Mtg. on Reduced Enrichment for Research and Test Reactors (RERTR), Cape Town, South Africa, Oct. 29 - Nov. 2, 2006. 〈http://www.rertr.anl.gov>

[16] Yeon Soo Kim, H.J. Ryu, G.L. Hofman, S.L. Hayes, M.R. Finlay, D. Wachs, G. Chang, Proc. Internat. Mtg. on Reduced Enrichment for Research and Test Reactors (RERTR), Cape Town, South Africa, Oct. 29 - Nov. 2, 2006. 〈http://www.rertr.anl.gov>

[17] G. L. Hofman, Yeon Soo Kim, H.J. Ryu, M.R. Finlay, Trans. Internat. Topical Meeting Research Reactor Fuel Management (RRFM), Lyon, France, Mar. 11-15, 2007. <http://www.euronuclear.org/meetings/rrfm2007/index.htm>

[18] G. L. Hofman, Yeon Soo Kim, J. Rest, Trans. Internat. Topical Meeting Research Reactor Fuel Management (RRFM), Hamburg, Germany, Mar. 2-5, 2008. <http://www.euronuclear.org/meetings/rrfm2008/index.htm> 
[19] D.D. Keiser, A.B. Robinson, D.E. Janney, J. F. Jue, Trans. Internat. Topical Meeting Research Reactor Fuel Management (RRFM), Hamburg, Germany, Mar. 2-5, 2008. <http://www.euronuclear.org/meetings/rrfm2008/index.htm>

[20] D.D. Keiser Jr., A.B. Robinson, J.F. Jue, P. Medvedev, D. M. Wachs, M.R. Finlay, J. Nucl. Mater., 393 (2009) 311.

[21] D.D. Keiser, J.F. Jue, A.B. Robinson, Proc. Internat. Mtg. on Reduced Enrichment for Research and Test Reactors (RERTR), Lisbon, Portugal, Oct. 10 - 14, 2010. $\langle$ http://www.rertr.anl.gov>

[22] J.M. Park, H.J. Ryu, Y.S. Lee, B.O. Yoo, Y.H. Jung, C.K. Kim, Yeon Soo Kim, Trans. Internat. Topical Meeting Research Reactor Fuel Management (RRFM), Hamburg, Germany, Mar. 2-5, 2008. <http://www.euronuclear.org/meetings/rrfm2008/index.htm>

[23] A. Leenaers, S. Van den Berghe, S. Dubois, J. Noirot, M. Ripert, P. Lemoine, Trans. Internat. Topical Meeting Research Reactor Fuel Management (RRFM), Hamburg, Germany, Mar. 2-5, 2008. <http://www.euronuclear.org/meetings/rrfm2008/index.htm>

[24] A. Leenaers, C. Detavernier, S. Van den Berghe, J. Nucl. Mater., 381 (2008) 242.

[25] A. Leenaers, S. Van de Berghe, F. Charollais, P. Lemoine, C. Jarousse, A. Röhrmoser, W. Petry, Proc. Internat. Meeting Reduced Enrichment for research Test Reactors (RERTR), Beijing, China, Nov. 1-6, 2009. 〈http://www.rertr.anl.gov>

[26] Yeon Soo Kim, G.L. Hofman, A.B. Robinson, Trans. Internat. Topical Meeting Research Reactor Fuel Management (RRFM), Vienna, Austria, Mar. 22-25, 2009. < http://www.euronuclear.org/meetings/rrfm2009/index.htm>

[27] J.M. Park, H.J. Ryu, J.H. Yang, Y.S. Lee, B.O. Yoo, Y.H. Jung, H. Kim, C.K. Kim, Yeon Soo Kim, G.L. Hofman, Proc. Internat. Mtg. on Reduced Enrichment for Research and Test Reactors (RERTR), Lisbon, Portugal, Oct. 10 - 14, 2010. 〈http://www.rertr.anl.gov>

[28] S. Dubois, J. Noirot, J. Gatt et al., Trans. Internat. Topical Meeting Research Reactor Fuel Management (RRFM), Lyon, France, Mar. 11-15, 2007. <http://www.euronuclear.org/meetings/rrfm2007/index.htm>

[29] A.L. Izhutov et al., Proc. Internat. Mtg. on Reduced Enrichment for Research and Test Reactors (RERTR), Beijing, China, November 1-5, 2009. 〈http://www.rertr.anl.gov>

[30] A. Izhutov, V. Alexandrov, A. Novosyolov, V. Starkov, A. Sheldyakov, V. Shishin, V. Iakovlev, I. Dobrikova, A. Vatulin, G. Kulakov, V. Suprun, Proc. Internat. Mtg. on Reduced Enrichment for Research and Test Reactors (RERTR), Lisbon, Portugal, Oct. 10 14, 2010. <http://www.rertr.anl.gov>

[31] Yeon Soo Kim, J.M. Park, H.J. Ryu, Y.H. Jung, G.L. Hofman, J. Nucl. Mater., 430 (2012) 50 . 
[32] N. Wieschalla, A. Bergmaier, P. Böni, G. Dollinger, R. Großmann, W. Petry, A. Röhrmoser, J. Schneider, J. Nucl. Mater., 357 (2006) 191.

[33] R. Jungwirth, H. Breitkreutz, W. Petry, A. Röhrmoser, W. Schmid, H. Palancher, C. Bertrand-Drira, C. Sabathier, X. Iltis, N. Tarisien and C. Jarousse, Proc. Internat. Mtg. on Reduced Enrichment for Research and Test Reactors (RERTR), Beijing, China, November 1-5, 2009. <http://www.rertr.anl.gov>

[34] R. Jungwirth, T. Zweifel, H.-Y. Chiang, W. Petry, F. Charollais, P. Lemoine, Y. Calzavara, H. Guyon, S. Van den Berghe, A. Leenaers, E. Koonen, B. Stepnik, C. Jarousse, Trans. Internat. Topical Meeting Research Reactor Fuel Management (RRFM), Prague, Czech Republic, Mar. 18-22, 2012.

[35] Yeon Soo Kim, G.L. Hofman, H.J. Ryu, J.M. Park, A.B. Robinson, D.M. Wachs, Nucl. Eng. Technol., 45 (2013) 827.

[36] T. Wiencek, Private communication, Argonne National Laboratory, 2013.

[37] A. Izhutov, V. Alexandrov, A. Novosyolov, V. Starkov, A. Sheldyakov, V. Shishin, V. Iakovlev, I. Dobrikova, A. Vatulin, G. Kulakov, V. Suprun, Proc. Internat. Mtg. on Reduced Enrichment for Research and Test Reactors (RERTR), Lisbon, Portugal, Oct. 10 14, 2010. http://www.rertr.anl.gov

[38] A. Leenaers, S. Van den Berghe, C. Detavernier, J. Nucl. Mater., 440 (2013) 220.

[39] H.J. Ryu, J.S. Park, J.M. Park, C.K. Kim, Nucl. Eng. Technol., 43 (2011) 159.

[40] H.J. Ryu, J.M. Park, K.H. Lee, B.O. Yoo, Y.H. Jung, Y.J. Jung, Y.S. Lee, Yeon Soo Kim, Trans. RRFM 2013, ENS, St. Petersburg, Russia, Apr. 21 -25, 2013. <http://www.euronuclear.org/meetings/rrfm2013/index.htm>

[41] C.K. Kim, K.H. Kim, S.J Jang, H.D. Jo, I.H. Kuk, Proc. Internat. Mtg. on Reduced Enrichment for Research and Test Reactors (RERTR), ANL/RERTR/TM-19, CONF9209266, Sept 27-Oct 1, 1992.

[42] W.J. Kim, H. Palancher, H.J. Ryu, J.M. Park, J.M. Nam, A. Bonnin, V. Honkimaki, F. Charollais, P. Lemoine, J. Alloys Compounds, 589 (2014) 94.

[43] J.H. Yang, Private communication, Korea Atomic Energy Research Institute, 2011.

[44] Yeon Soo Kim, G.L. Hofman, J. Nucl. Mater., 419 (2011) 291.

[45] Yeon Soo Kim, G.L. Hofman, J.S. Cheon, J. Nucl. Mater., 436 (2013) 14.

[46] Yeon Soo Kim, G.L. Hofman, J. Nucl. Mater., 410 (2011) 1.

[47] R.B. Mathews, Irradiation performance of nitride fuels, LA-UR-93-2392, Los Alamos National Laboratory, 1993 
[48] Yeon Soo Kim, G.L. Hofman, A.B. Robinson, D.M. Wachs, H.J. Ryu, J.M. Park, J.H. Yang, J. Nucl. Mater., 427 (2012) 233.

[49] J. Gan, D.D. Keiser Jr., B.D. Miller, A.B. Robinson, J.F. Jue, P. Medvedev, D.M. Wachs, J. Nucl. Mater., 424 (2012) 43.

[50] G.L. Hofman, Private communication, Argonne National Laboratory, 2008.

[51] H.J. Ryu, Yeon Soo Kim, Nucl. Eng. Technol., 46 (2014) 159.

[52] B. Ye, J. Rest, Yeon Soo Kim, A description of the mechanistic DART-THERMAL dispersion fuel performance code and application to irradiation behavior analysis of UMo/Al, ANL/GTRI/TM/13/3, Argonne National Laboratory, March 2013.

[53] H.J. Ryu, J.M. Park, Y.J. Jeong, K.H. Lee, Y.S. Lee, C.K. Kim, Yeon Soo Kim, Nucl. Eng. Technol., 45 (2013) 847. 
Table 1 KOMO-5 irradiation test data

\begin{tabular}{|c|c|c|c|c|c|c|c|}
\hline $\begin{array}{c}\text { Specimen } \\
\text { ID }\end{array}$ & $\begin{array}{c}\text { Nominal } \\
\text { fuel } \\
\text { composition } \\
(\mathrm{wt} \%)^{*}\end{array}$ & $\begin{array}{c}\text { U- } \\
\text { loading } \\
\left(\mathrm{gU} / \mathrm{cm}^{3}\right. \\
\text { meat })\end{array}$ & $\begin{array}{c}\text { Average } \\
\text { fuel } \\
\text { particle } \\
\text { size }(\mu \mathrm{m})\end{array}$ & $\begin{array}{c}\text { Fission } \\
\text { density } \\
\left(10^{21}\right. \\
\mathrm{f} / \mathrm{cm}^{3} \text { in } \\
\mathrm{U}-\mathrm{Mo})\end{array}$ & $\begin{array}{c}\text { Test } \\
\text { duration } \\
(\mathrm{EFPD})\end{array}$ & $\begin{array}{c}\text { Life- } \\
\text { average } \\
\text { fission } \\
\text { rate } \\
\left(10^{14}\right. \\
\mathrm{f} / \mathrm{cm}^{3} \mathrm{U}- \\
\text { Mo-s })\end{array}$ & $\begin{array}{c}\text { Life- } \\
\text { average } \\
\text { fuel center } \\
\text { temperature } \\
\left({ }^{\circ} \mathrm{C}\right)\end{array}$ \\
\hline 557-SI1 & U-7Mo/Al & 5 & 175 & 5 & 228 & 2.5 & 158 \\
\hline 676-NI1 & U-7Mo/Al & 5 & 175 & 4.6 & 228 & 2.3 & 147 \\
\hline
\end{tabular}

* The actual values from a chemical analysis are U-6.2wt\%Mo for 557-SI1 and U-7.0wt\%Mo for 676-NI1.

Table 2 DART prediction results for U-Mo, Al matrix, IL volume fractions and fuel meat swelling for three fuel particle sizes for 557-SI1 irradiation condition

\begin{tabular}{|c|c|c|c|c|c|}
\hline $\begin{array}{c}\text { Average } \\
\text { fuel particle } \\
\text { size }(\mu \mathrm{m})\end{array}$ & $\begin{array}{c}\text { IL thickness } \\
(\mu \mathrm{m})\end{array}$ & $\begin{array}{c}\text { IL volume } \\
\text { fraction } \\
(\%)\end{array}$ & $\begin{array}{c}\text { U-Mo }{ }^{\text {a }} \\
\text { volume } \\
\text { fraction }(\%)\end{array}$ & $\begin{array}{c}\text { Al matrix } \\
\text { volume } \\
\text { fraction }(\%)\end{array}$ & $\begin{array}{c}\text { Fuel meat } \\
\text { swelling } \\
(\%)\end{array}$ \\
\hline 175 & 22 & 27 & 32 & 41 & 9 \\
\hline 120 & 22 & 42 & 29 & 29 & 10 \\
\hline 70 & 22 & 79 & 21 & $0^{\mathrm{b}}$ & 14 \\
\hline
\end{tabular}

a: As-fabricated fuel volume fraction was $30 \%$.

b: Al matrix was completely consumed at 212 EFPD. 


\section{Figure captions}

Fig. 1 Schematic of U-silicide coating method.

Fig. 2 SEM image of U-silicide coating on a U-7Mo particle and superimposed EDS concentrations of $\mathrm{U}, \mathrm{Mo}, \mathrm{Si}$, and $\mathrm{Al}$ across the coating.

Fig. 3 Schematic of U-nitride coating method.

Fig. 4 SEM image and elemental concentration of the periphery of a U-nitride coated U-7Mo particle

Fig. 5 Fuel rod test bundle and schematic of cross section of the test rod bundle. 557-SI1 is the U-silicide coated fuel rod and 676-NI1 is the U-nitride coated fuel rod. Rod positions $1-6$ were loaded with Al dummy rods and test rods were loaded in rod positions $7-18$.

Fig. 6 Power and meat-center temperature histories of 557-SI1 and 676-NI1 rods at their respective PIE locations.

Fig. 7 Optical micrographs of the radial cross sections of 557-SI1 and 676-NI1. The darkest phase is $\mathrm{U}-7 \mathrm{Mo}$, the brightest is $\mathrm{Al}$, and the gray in between is interaction phase. The coating is not visible in this low magnification image.

Fig. 8 SEM images showing EDS line scan tracks and EDS concentration data across ILs: (A) and (a) thin IL of U-silicide coated particle, (B) and (b) thick IL of U-silicide coated particle, (C) and (c) IL of U-nitride coated particle. The numbers close to the arrows in the images are the EPMA scan lengths.

Fig. 9 Optical post-irradiation images of (a) U-silicide coated U-7Mo in Al (557-SI1), and (b) Unitride coated U-7Mo in $\mathrm{Al}$ (676-NI1).

Fig. 10 Post-irradiation SEM images of U-silicide coated U-7Mo and U-nitride coated U7Mo dispersion in $\mathrm{Al}$. 

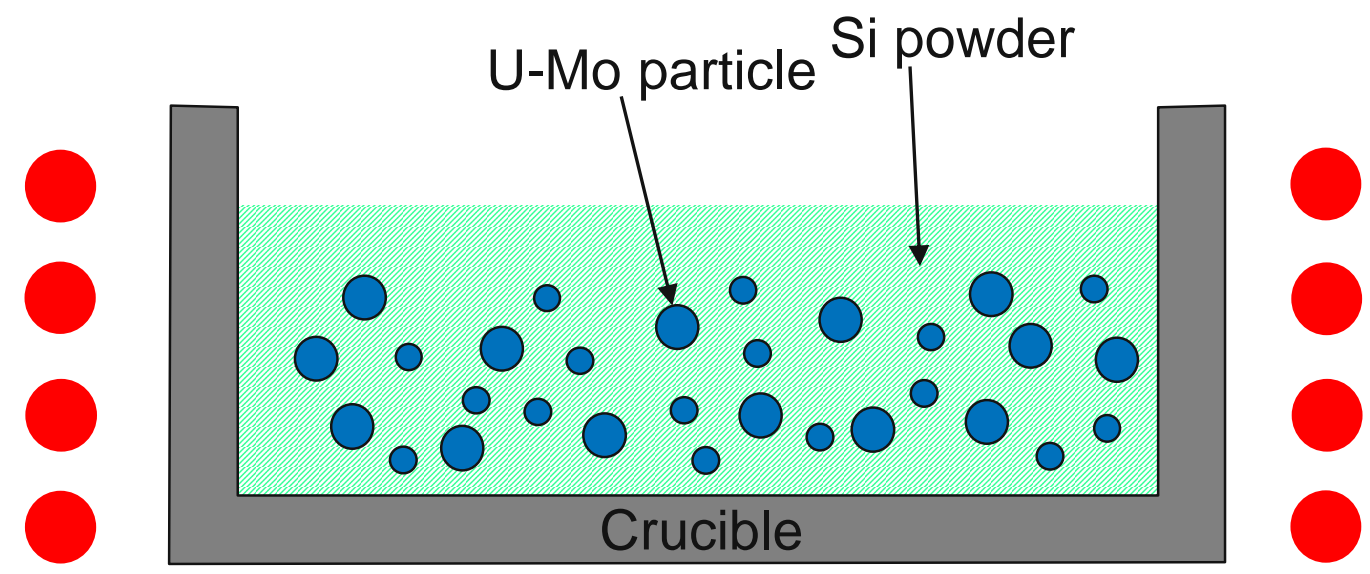

Vacuum heating at $1000^{\circ} \mathrm{C}$ for 1 hour

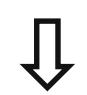

Sieve
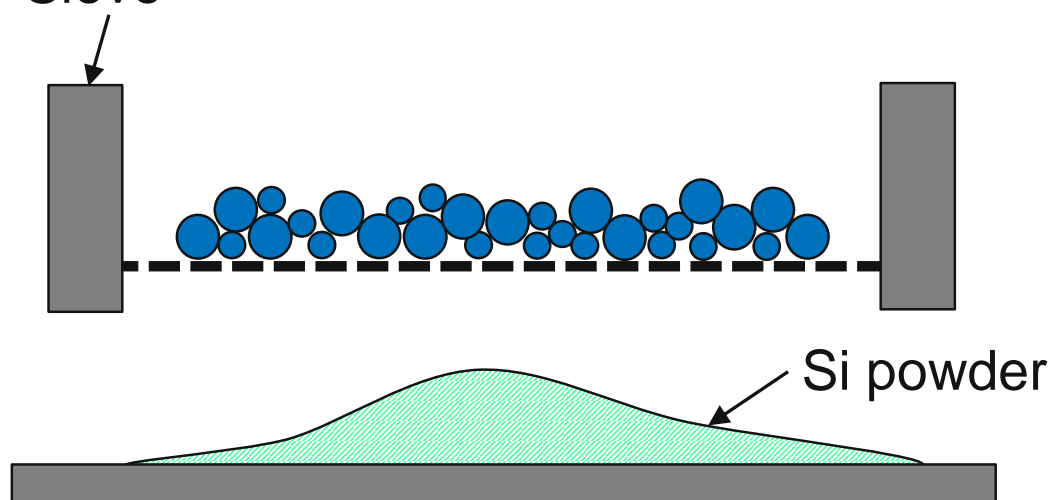

Fig. 1 Schematic of U-silicide coating method. 


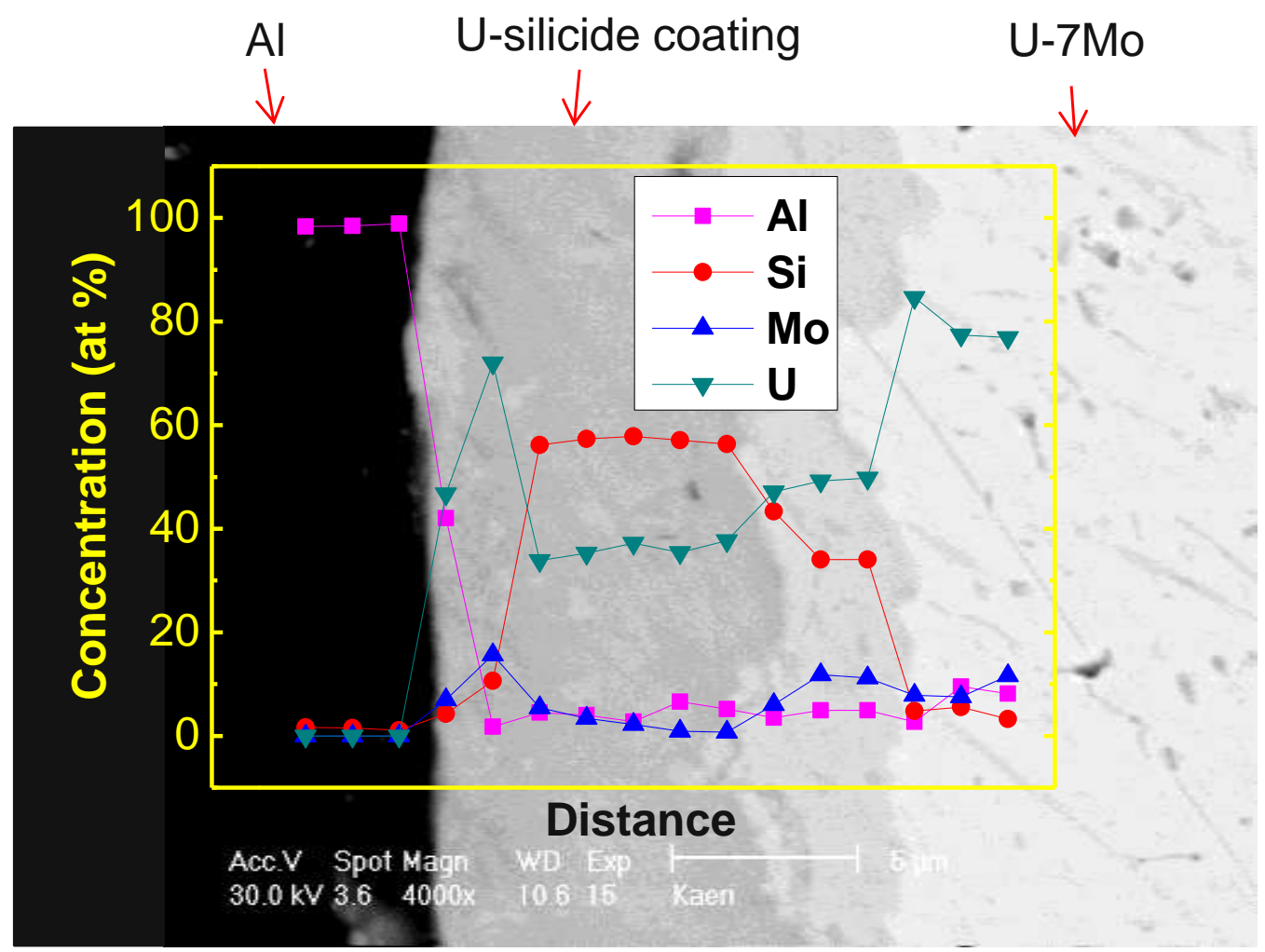

Fig. 2 SEM image of U-silicide coating on a U-7Mo particle and superimposed EDS concentrations of $\mathrm{U}, \mathrm{Mo}, \mathrm{Si}$, and $\mathrm{Al}$ across the coating. 


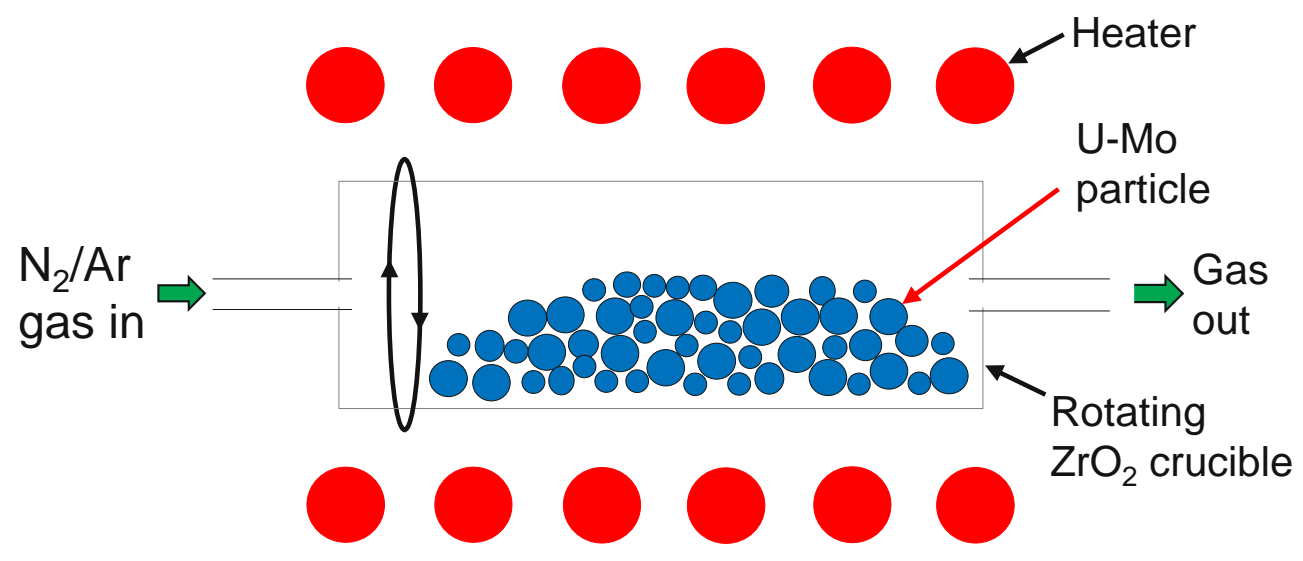

Fig. 3 Schematic of U-nitride coating method. 


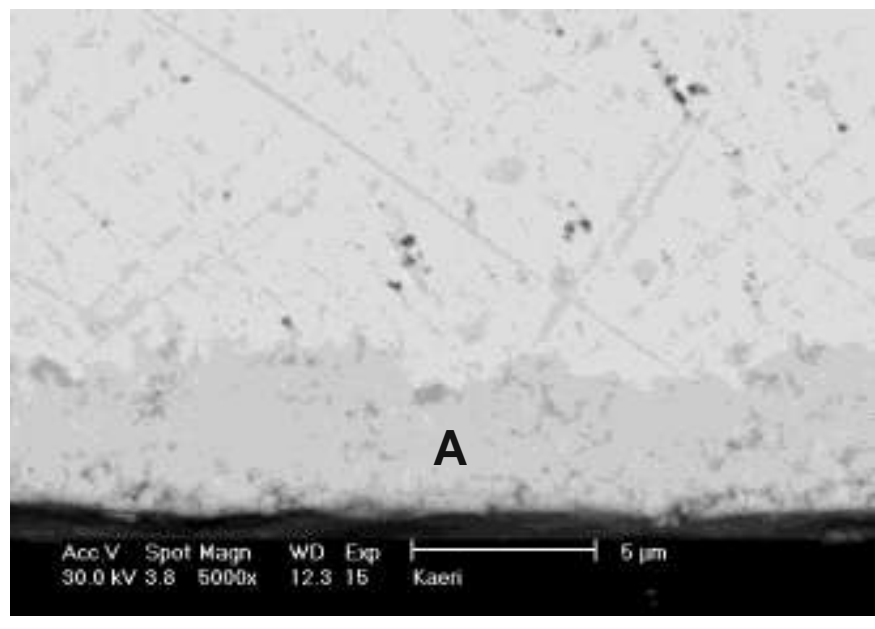

\begin{tabular}{c|c}
\hline $\begin{array}{c}\text { Element } \\
\text { (at\%) }\end{array}$ & $\mathrm{A}$ \\
\hline $\mathrm{N}$ & 70 \\
$\mathrm{O}$ & 9 \\
Mo & 1 \\
$\mathrm{U}$ & 20 \\
\hline
\end{tabular}

Fig. 4 SEM image and elemental concentration of the periphery of a U-nitride coated U-7Mo particle 


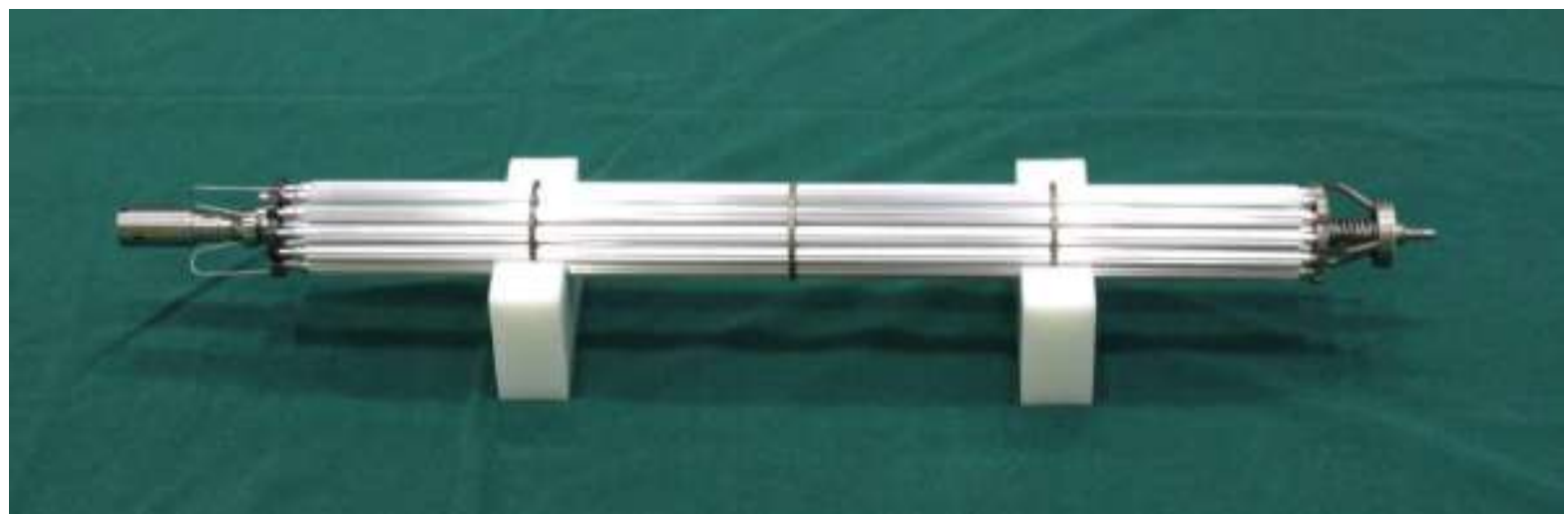

(a) Test rod assembly

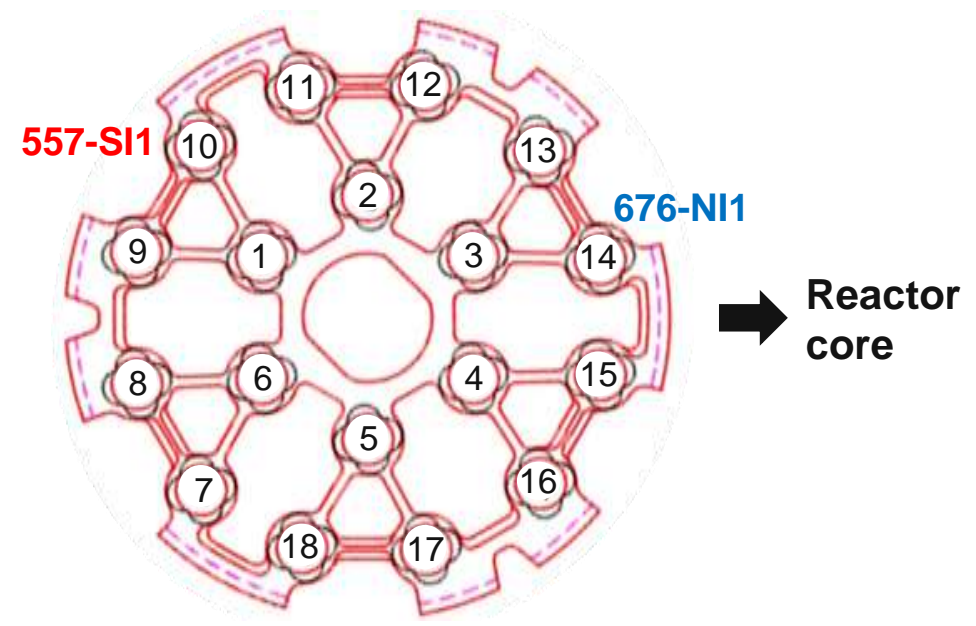

(b) Schematic of the cross section of the test rod assembly

Fig. 5 Fuel rod test bundle and schematic of cross section of the test rod bundle. 557-SI1 is the U-silicide coated fuel rod and 676-NI1 is the U-nitride coated fuel rod. Rod positions $1-6$ were loaded with Al dummy rods and test rods were loaded in rod positions $7-18$. 


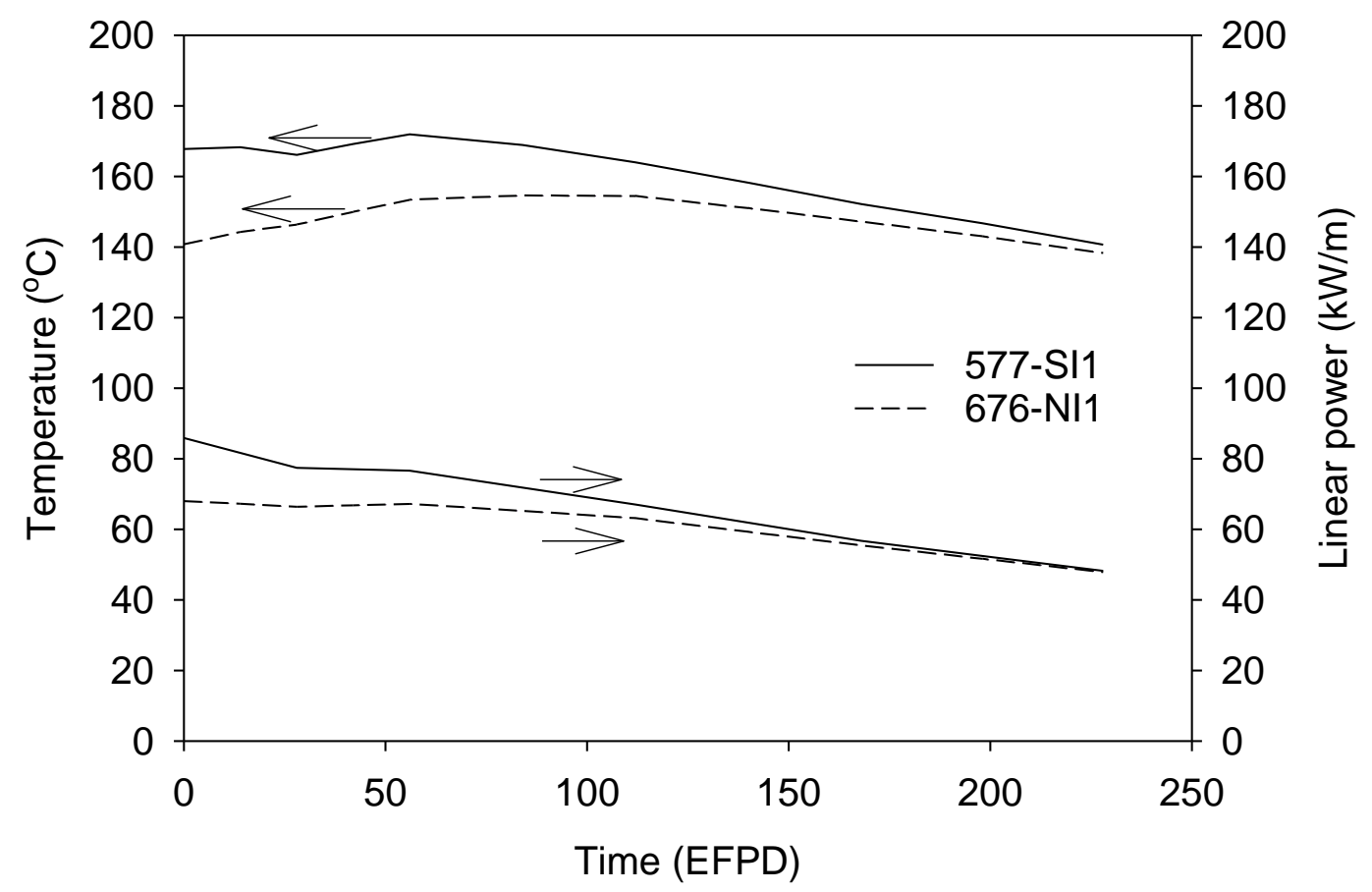

Fig. 6 Power and meat-center temperature histories of 557-SI1 and 676-NI1 rods at their respective PIE locations. 


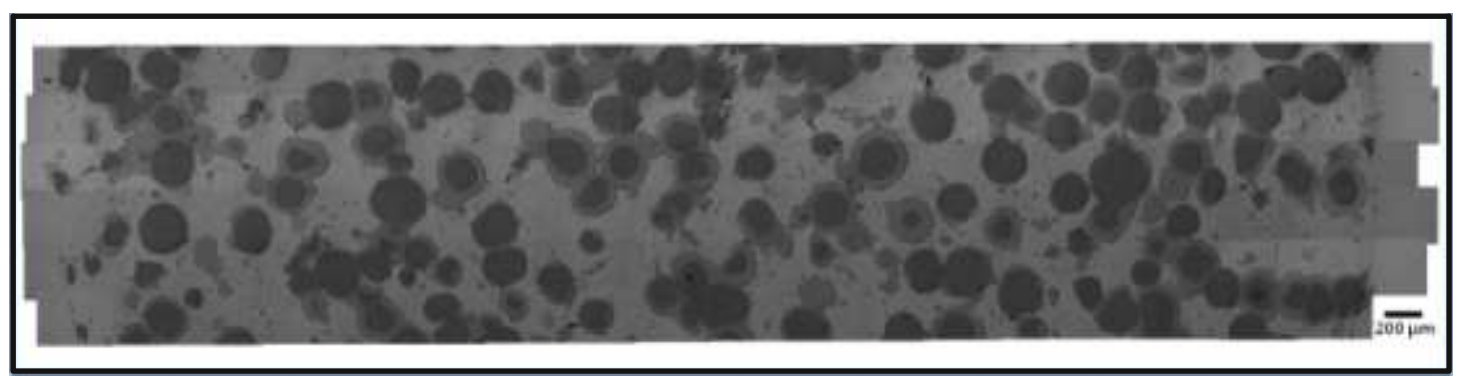

(a) 557-SI1

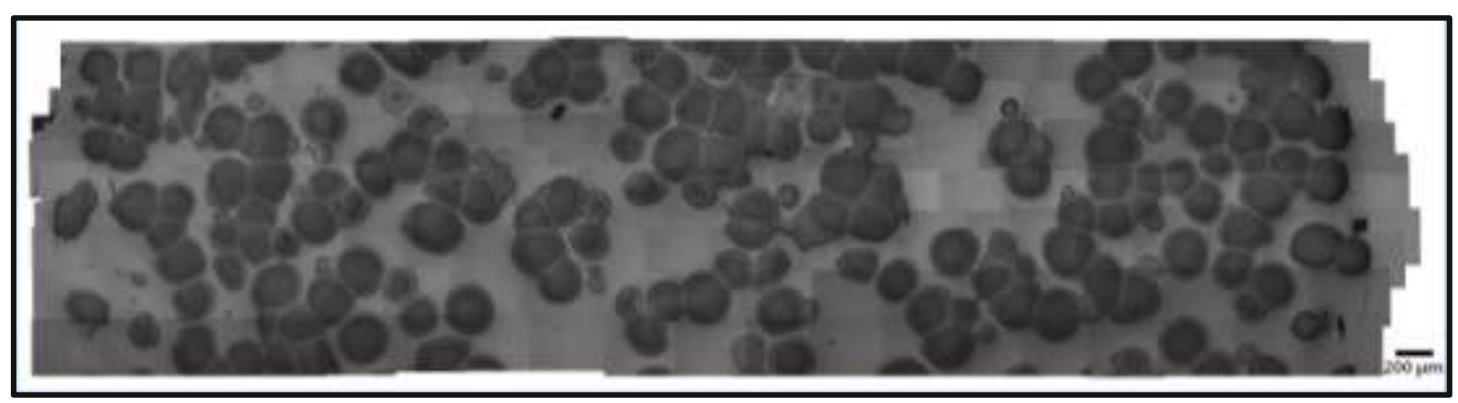

(b) 676-NI1

Fig. 7 Optical micrographs of the radial cross sections of 557-SI1 and 676-NI1. The darkest phase is $\mathrm{U}-7 \mathrm{Mo}$, the brightest is $\mathrm{Al}$, and the gray in between is interaction phase. The coating is not visible in this low magnification image. 

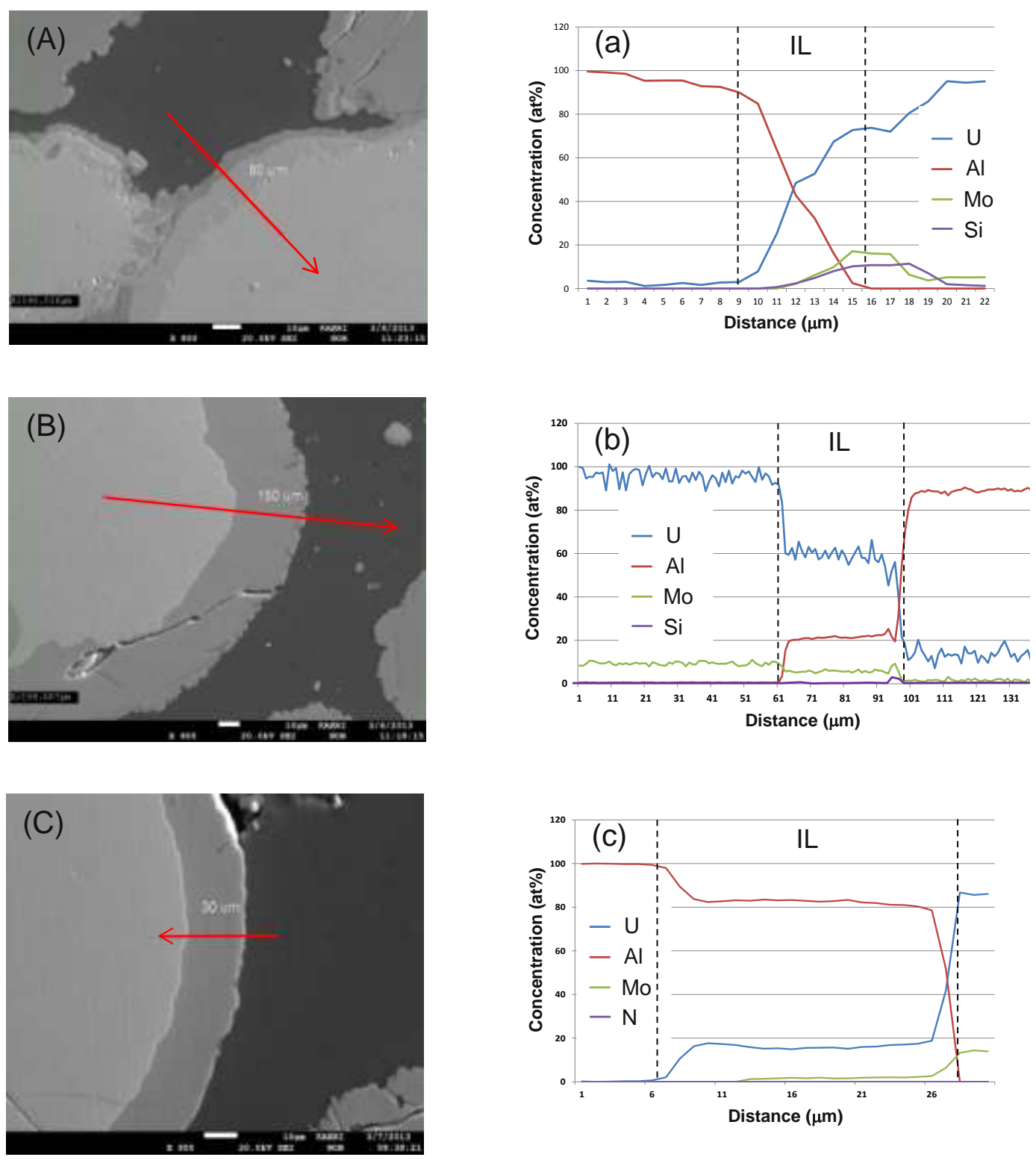

Fig. 8 SEM images showing EDS line scan tracks and EDS concentration data across ILs: (A) and (a) thin IL of U-silicide coated particle, (B) and (b) thick IL of U-silicide coated particle, (C) and (c) IL of U-nitride coated particle. The numbers close to the arrows in the images are the EPMA scan lengths. 


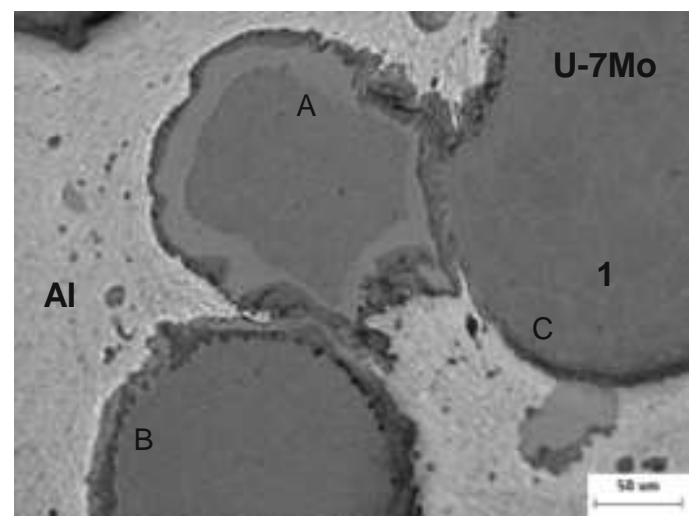

(a)

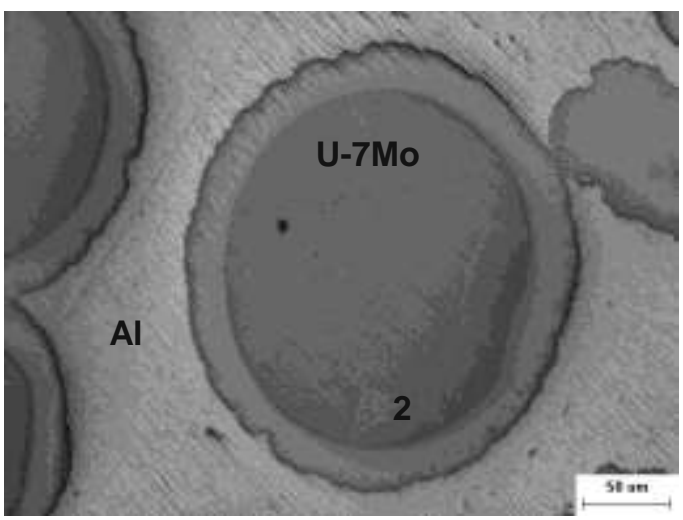

(b)

Fig. 9 Optical post-irradiation images of (a) U-silicide coated U-7Mo in Al (557-SI1), and (b) Unitride coated U-7Mo in $\mathrm{Al}$ (676-NI1). 


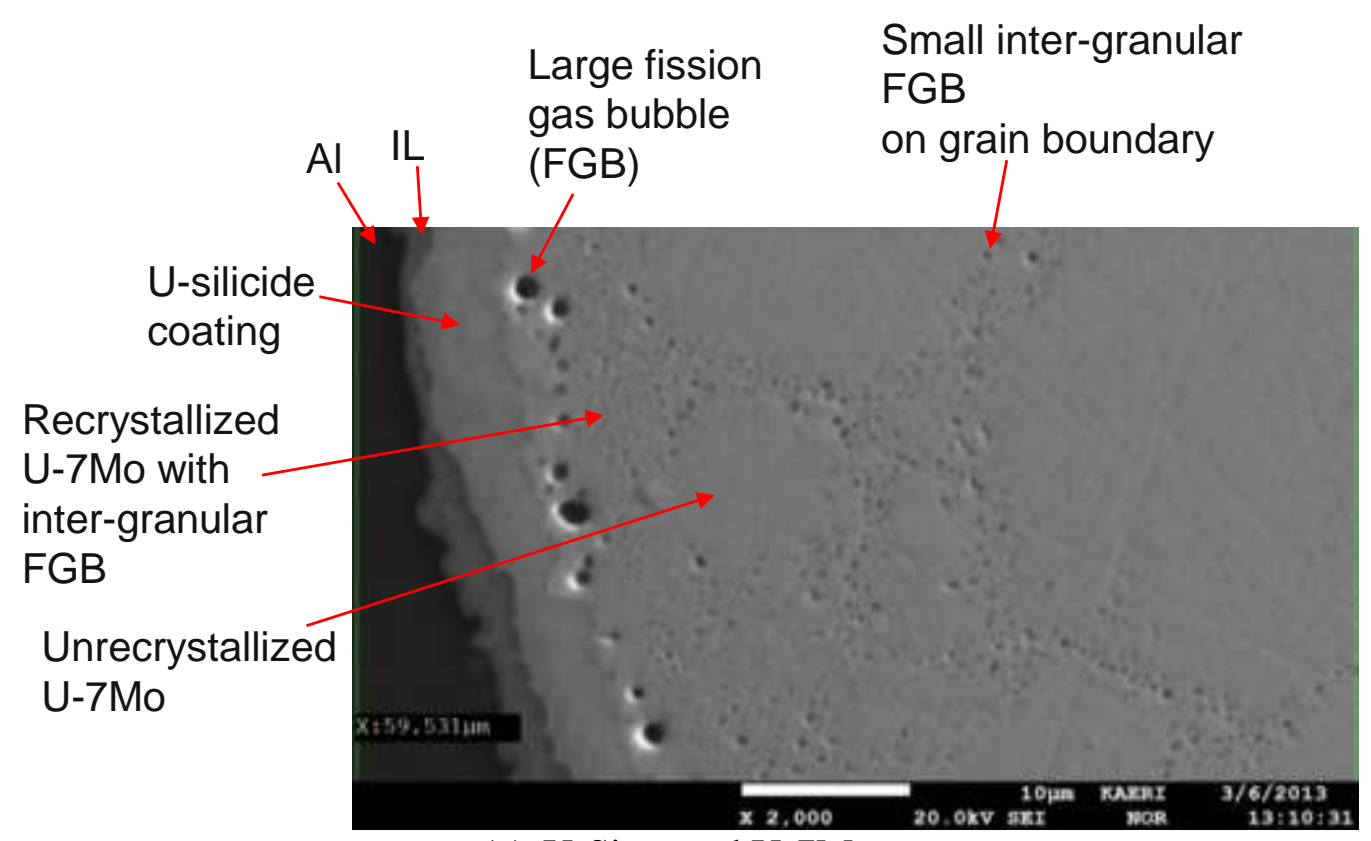

(a) U-Si coated U-7Mo

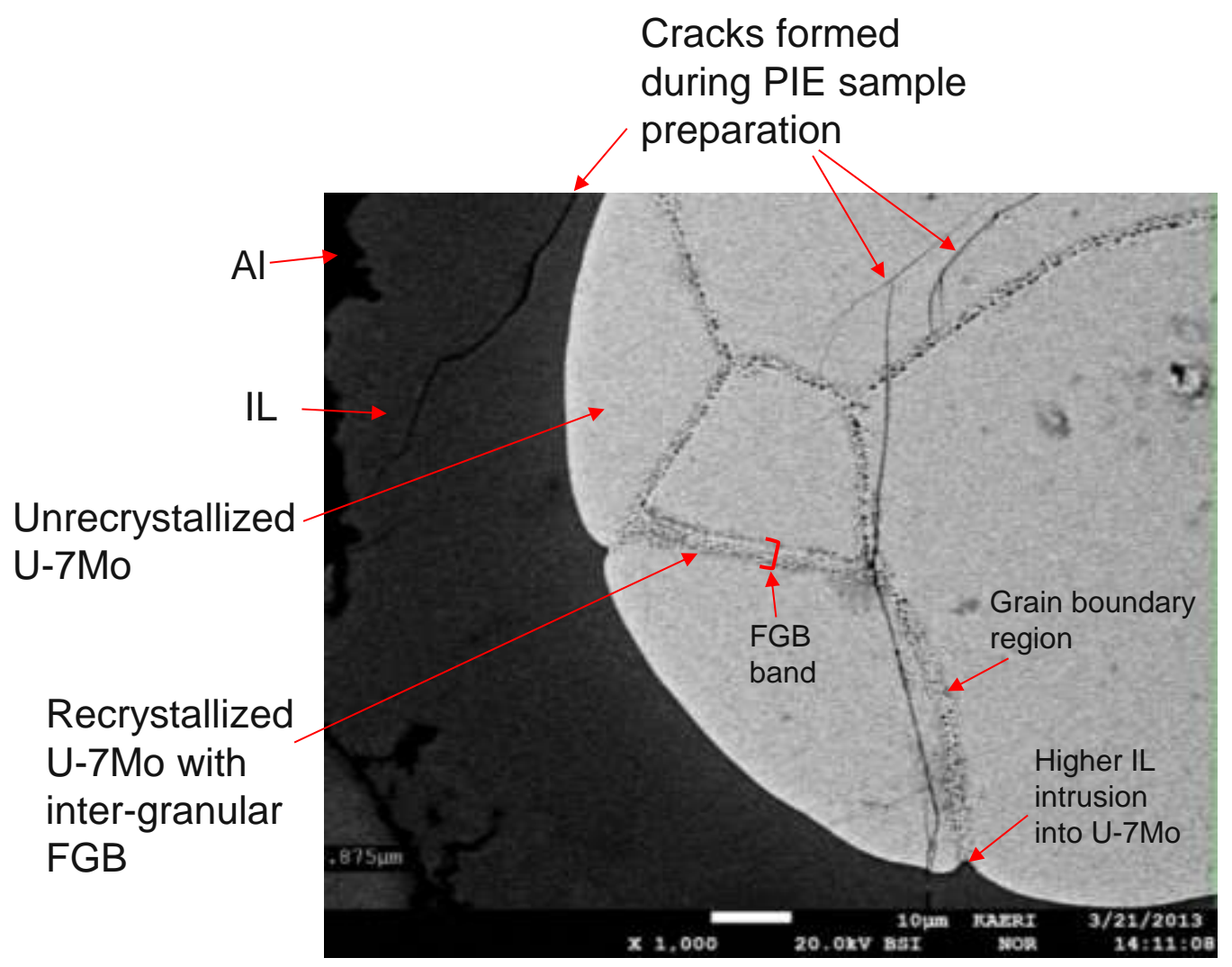

(b) U-nitride coated U-7Mo

Fig. 10 Post-irradiation SEM images of U-silicide coated U-7Mo and U-nitride coated U-7Mo dispersion in $\mathrm{Al}$. 